\title{
Polymorphisms in the glucocorticoid receptor co-chaperone FKBP5 predict persistent musculoskeletal pain after traumatic stress exposure
}

Andrey V. Bortsov, MD, PhD ${ }^{\star}, 1,2$, Jennifer E. Smith, BS ${ }^{\star}, 1,2$, Luda Diatchenko, MD, PhD ${ }^{3}$, April C. Soward, MPH ${ }^{1,2}$, Jacob C. Ulirsch, BS ${ }^{1,2}$, Catherine Rossi, RN, SANE-A ${ }^{4}$, Robert A. Swor, MD $^{5}$, William E. Hauda, MD ${ }^{6}$, David A. Peak, MD ${ }^{7}$, Jeffrey S. Jones, MD ${ }^{8}$, Debra Holbrook, RNC, SANE ${ }^{9}$, Niels K. Rathlev, MD ${ }^{10}$, Kelly A. Foley, MD ${ }^{11}$, David C. Lee, MD ${ }^{12}$, Renee Collette, RN, SANE ${ }^{13}$, Robert M. Domeier, MD ${ }^{14}$, Phyllis L. Hendry, MD ${ }^{15}$, and Samuel A. McLean, MD, MPH ${ }^{1,2,16}$

${ }^{1}$ TRYUMPH Research Program ${ }^{2}$ Anesthesiology, University of North Carolina, Chapel Hill, NC ${ }^{3}$ Regional Center for Neurosensory Disorders, University of North Carolina, Chapel Hill, North Carolina ${ }^{4}$ Forensic Nursing Program, Medicine, Cone Health System, Greensboro, North Carolina ${ }^{5}$ Emergency Medicine, William Beaumont Hospital, Royal Oak, Michigan ${ }^{6}$ Forensic Assessment and Consultation Teams, Inova Fairfax Hospital, Falls Church, Virginia ${ }^{7}$ Emergency Medicine, Massachusetts General Hospital, Boston, Massachusetts ${ }^{8}$ Emergency Medicine, Spectrum Health System, Grand Rapids, Michigan ${ }^{9}$ SANE Program, Mercy Medical Center, Baltimore, Maryland ${ }^{10}$ Emergency Medicine, Baystate Medical Center, Springfield, Massachusetts ${ }^{11}$ Department of Emergency Medicine, Sentara Norfolk Hospital, Norfolk, Virginia ${ }^{12}$ Emergency Medicine, North Shore University Hospital, Manhasset, New York ${ }^{13}$ SANE Program, Mission Health System, Asheville, North Carolina ${ }^{14}$ Emergency Medicine, Saint Joseph Mercy Health System, Ypsilanti, Michigan ${ }^{15}$ Emergency Medicine, University of Florida, Jacksonville, Florida ${ }^{16}$ Emergency Medicine, University of North Carolina, Chapel Hill, NC

\section{Abstract}

Individual vulnerability factors influencing the function of the hypothalamic-pituitary-adrenal (HPA) axis may contribute to the risk of the development of persistent musculoskeletal pain after traumatic stress exposure. The objective of the study was to evaluate the association between polymorphisms in the gene encoding FK506 binding protein 51, FKBP5, a glucocorticoid receptor co-chaperone, and musculoskeletal pain severity six weeks after two common trauma exposures. The study included data from two prospective emergency department-based cohorts: a discovery cohort ( $n=949)$ of European Americans experiencing motor vehicle collision and a replication cohort of adult European American women experiencing sexual assault $(n=53)$. DNA was collected from trauma survivors at the time of initial assessment. Overall pain and neck pain six weeks after trauma exposure were assessed using a 0-10 numeric rating scale. After adjustment

(C) 2013 International Association for the Study of Pain. Published by Elsevier B. V. All rights reserved. Correspondence: Samuel McLean, MD, MPH, University of North Carolina, Medical School Wing C CB\#7010, Chapel Hill, NC 27599-7010, Phone: 919-843-5931, Fax: 919-966-7193, smclean@aims.unc.edu.

First two authors contributed equally to manuscript

Publisher's Disclaimer: This is a PDF file of an unedited manuscript that has been accepted for publication. As a service to our customers we are providing this early version of the manuscript. The manuscript will undergo copyediting, typesetting, and review of the resulting proof before it is published in its final citable form. Please note that during the production process errors may be discovered which could affect the content, and all legal disclaimers that apply to the journal pertain.

Conflict of interest: Dr. Diatchenko is a co-founder and equity stock holder in Algynomics, Inc. Other authors declare no conflict of interest. 
for multiple comparisons, six FKBP5 polymorphisms showed significant association (minimum $\mathrm{p}$ $<0.0001$ ) with both overall and neck pain in the discovery cohort. The association of rs3800373, rs9380526, rs9394314, rs2817032, and rs2817040 with neck pain and/or overall pain six weeks after trauma was replicated in the sexual assault cohort, showing the same direction of the effect in each case. The results of this study indicate that genetic variants in FKBP5 influence the severity of musculoskeletal pain symptoms experienced during the weeks after motor vehicle collision and sexual assault. These results suggest that glucocorticoid pathways influence the development of persistent post-traumatic pain, and that such pathways may be a target of pharmacologic interventions aimed at improving recovery after trauma.

\section{INTRODUCTION}

Traumatic events are common in life. Two examples of traumatic events that are frequently experienced by US civilians are motor vehicle collision (MVC) and sexual assault: each year more than eleven million Americans experience an MVC and nearly 700,000 women are sexually assaulted $[1,40]$. Persistent musculoskeletal pain is commonly reported by survivors of such events $[21,28,43]$ and results in substantial suffering and diminished health $[19,20,45,50]$. However, most individuals with persistent post-traumatic pain do not experience major tissue injury at the time of trauma [25,38], and diagnostic evaluations of patients complaining of posttraumatic musculoskeletal pain often cannot identify a responsible tissue lesion $[21,33,41]$. As a result, patients with persistent post-traumatic musculoskeletal pain are often stigmatized (e.g. as reporting symptoms for financial gain).

In addition to potentially resulting in tissue injury, traumatic events are potent stressors which activate neurobiological stress response systems. Increasing evidence suggests that these systems modulate neurosensory processing [14,34], and that the activation of physiologic stress systems such as the hypothalamic-pituitary-adrenal (HPA) axis may contribute to the development of persistent posttraumatic pain in vulnerable individuals $[17,31]$. For example, variation in HPA axis function has been found to predict widespread musculoskeletal pain development in community samples [31] and pain persistence in patients with low back pain undergoing surgery [18].

If HPA axis function during and after trauma exposure affects the severity of persistent musculoskeletal pain experienced by trauma survivors, then inherited differences in the function of important components of the HPA axis would also be expected to influence individual vulnerability to post-traumatic pain. One important component of the HPA axis is the intracellular protein FK506 binding protein 51 (FKBP5) [39,55]. FKBP5 interacts with heat shock protein 90 , which binds to the glucocorticoid receptor and regulates glucocorticoid receptor sensitivity $[39,47,55]$. Both genetic polymorphisms within the gene encoding FKBP5, FKBP5, and reduced FKBP5 expression have been shown to influence the risk of post-traumatic psychological sequelae $[6,26,49]$. However, the influence of genetic polymorphisms in FKBP5 on post-traumatic pain outcomes has never been assessed.

In this study we evaluated the association between genetic polymorphisms in FKBP5 and musculoskeletal pain severity six weeks after two common trauma exposures, MVC and sexual assault. We hypothesized that one or more FKBP5 single nucleotide polymorphisms (SNPs) would influence the severity of persistent pain after both types of trauma. We assessed this hypothesis using a prospective observational study of pain outcomes after MVC as a discovery cohort and a prospective observational study of pain outcomes after sexual assault as a replication cohort. Neck pain intensity and overall pain intensity six weeks after trauma were selected pre-hoc as the two study outcome measures. Neck pain intensity was selected because pain in the neck region after MVC is a major public health 
problem [21], and because neck pain also appears to be common after sexual assault [33]. Overall pain intensity was selected because it provides a summary assessment of pain severity across body regions.

\section{METHODS}

\section{Motor vehicle collision cohort}

Study design and population-The details of the MVC study have been reported [37]. In brief, individuals $\geq 18$ and $\leq 65$ years of age presenting to one of eight EDs in four nofault insurance states within 24 hours of MVC who did not have fracture or other injury requiring hospital admission were enrolled. Patients who were not alert and oriented were excluded, as were pregnant patients, prisoners, patients unable to read and understand English, patients taking a $\beta$-adrenoreceptor antagonist, or patients taking opioids above a total daily dose of $30 \mathrm{mg}$ of oral morphine or equivalent. In addition, because genetic analyses are potentially biased by population stratification [9], enrollment was also limited to non-Hispanic whites (the most common ethnicity at study sites). Informed consent was obtained from all participants and Institutional Review Board (IRB) approval was obtained at all study sites.

DNA collection and genotyping - Study personnel collected blood samples at the time of enrollment using PAXgene DNA tubes. Following DNA purification (PAXgene blood DNA kit, QIAGEN), genotyping using the Sequenom platform was performed at thirty-three SNPs (Supplementary Table 1) selected to cover haplotype diversity at the FKBP5 gene locus. Two Hapmap samples and two repeat samples were included in each genotyping batch (96 samples). Repeated genotyping demonstrated greater than $98 \%$ call agreement.

Assessments-Overall pain intensity in the ED, neck pain intensity in the ED, and average pain during the month prior to MVC were assessed using verbal 0-10 numeric rating scales (NRSs). Verbal scores have advantages in acute care settings, and verbally administered NRSs have been validated as a substitute for Visual Analog Scales in acute pain measurement in the ED [5]. Average neck pain intensity in the past week (0-10 NRS) and average overall pain intensity in the past week (0-10 NRS) were evaluated six weeks after the MVC via web-based questionnaire or telephone interview. Post-traumatic stress disorder symptoms were evaluated at week six using the Impact of Event Scale - Revised (IES-R) [11].

\section{Sexual assault cohort}

Study design and population-The methods of the sexual assault study have been reported [2,33]. In brief, women 18 years of age or older who presented to one of ten Sexual Assault Nurse Examiner (SANE) programs in four states for medical care within 48 hours of sexual assault were recruited. Women unable to give informed consent (e.g., due to intoxication) were excluded, as were women who were hospitalized after assault, lived with their assailant, were prisoners, were pregnant, did not have a telephone, and/or did not live within driving distance for follow-up interviews. For purposes of the current replication analyses, only data from European Americans were analyzed. IRB approval was obtained at all study sites and all study participants provided written informed consent.

DNA collection and genotyping - Saliva specimens were obtained at one week followup evaluations using Oragene DNA Self-Collection Kits. Following DNA purification (PAXgene blood DNA kit, QIAGEN), genotyping was performed within the same batches as MVC cohort samples and at the same thirty-two SNPs. As described above, Hapmap 
samples and two repeat samples were included in each genotyping batch to ensure genotypic accuracy and reliability; repeated genotyping demonstrated greater than $98 \%$ call agreement.

Assessments-Neck pain at the time of presentation for emergency care (within forty eight hours of sexual assault) was evaluated as part of a brief self-report questionnaire assessing current pain intensity in each of eight body regions (head and face, neck, breast, arms, abdomen, back, genital and pelvic, and legs). One week after the assault, sexual assault survivors completed an in-person computerized self-report questionnaire which included an assessment of current musculoskeletal pain symptoms (overall pain, 0-10 NRS) and pain symptoms during the week prior to assault (0-10 NRS). Six weeks after assault, consenting women sexual assault survivors completed an additional in-person computerized self-report questionnaire which included an assessment of average neck pain intensity in the past week (0-10 NRS) and average overall pain intensity in the past week (0-10 NRS).

\section{Analyses}

SNPs that were not in Hardy-Weinberg equilibrium (HWE), SNPs with call rates below $85 \%$, and SNPs with minor allele frequency less than 0.05 were excluded from analyses. Linkage disequilibrium between FKBP5 SNPs was explored in each cohort separately by calculating Levontin D' and squared correlation $\mathrm{r}^{2}$ using HaploView [3]. Tag SNPs for statistical analyses were selected by using the Tagger procedure implemented in Haploview with the threshold $\mathrm{r}^{2}=0.8$ [12].

The relationship between FKBP5 polymorphisms and pain outcomes in the MVC discovery cohort were assessed using general linear models. Three genetic models were used: an additive model (genotype is coded as the number of minor alleles, i.e. 0,1 , or 2 ), a dominant model (homozygous for major allele vs. other), and a recessive model (homozygous for minor allele vs. other). Study site was included as a covariate in these models to adjust for potential genetic heterogeneity between study recruitment centers. False discovery rate (FDR) was controlled for when determining statistical significance [4]. FKBP5 haplotypes and their population frequencies were estimated from MVC cohort data using the expectation-maximization algorithm implemented in HaploView and verified using Bayesian estimation of haplotype frequencies implemented in SAS 9.2 [27].

SNPs significantly associated with both neck pain and overall pain in the MVC discovery cohort were evaluated in the sexual assault replication cohort using general linear models adjusted for study site. Replication cohort analyses employed the genetic model that provided the best fit in discovery cohort analyses (dominant model). Because linear models applied to small samples are less robust to the violation of non-normality assumptions, significance of the genetic association in the sexual assault cohort was determined via permutation using the $1 \mathrm{mPerm}$ package for R (http://www.R-project.org). Permutations were run until the $\mathrm{p}$-value $95 \%$ confidence interval was within $\pm 10 \%$ of the estimated $\mathrm{p}$-value. Due to the increased pre-test probability of significance when using significant SNPs from the discovery cohort, and the smaller number of tests performed, in replication cohort analyses $p<0.05$ was deemed statistically significant.

For longitudinal analyses using repeated measures of pain over time, linear mixed models were used (SAS 9.2, SAS Institute Inc., Cary, NC). Heterogeneity of genotype effect across different time points was accounted for by specifying a time $\times$ genotype interaction term. Correlation between outcome measures within each subject was accounted for by specifying an unstructured covariance matrix of measurement errors. Least square means and their standard errors were output from the model and post-hoc pairwise comparisons of means were performed. 


\section{RESULTS}

\section{Participants}

Discovery and replication cohort characteristics are shown in Table 1. Compared to MVC survivors, sexual assault survivors were younger, less educated, and reported higher levels of pre-trauma pain. Sixty one percent $(n=575)$ of MVC survivors were women, whereas all sexual assault survivors $(n=53)$ were women.

\section{Genotyping results}

Of the 33 selected SNPs, 32 (97\%) were successfully genotyped in both cohorts (Supplementary Table 1). All genotyped SNPs were in Hardy-Weinberg equilibrium ( $\mathrm{p}>$ 0.05). One SNP (rs3798346) had a low call rate (77\%) and was excluded from analyses. All other SNPs had excellent call rates ( $\geq 99 \%$ ). Six SNPs were excluded because of a minor allele frequency $<0.05$ (rs16878806, rs28675670, rs13192954, rs7762760, rs34110646, and rs7751693)

All genotyped SNPs were in linkage disequilibrium (average pairwise D' $=0.88$, see Supplementary Figure 1). To avoid redundant analyses of highly associated SNPs, fourteen tagging SNPs were selected by using the Tagger procedure (Haploview software) and threshold $\mathrm{r}^{2}=0.8$ (Table 2). In addition, SNP rs3800373 was retained in analyses because of its previous association with stress-related psychological sequelae $[6,26]$.

\section{Association of FKBP5 Polymorphisms with Musculoskeletal Pain after MVC}

A dominant model provided the best fit to the data (Supplementary Table 2) and was used for all subsequent analyses. After adjustment for study site, and controlling for overall false discovery rate (FDR), eight SNPs predicted neck pain severity six weeks after MVC (Table 2). Six of these SNPs also predicted overall pain (Table 2). Across SNPs and across both pain outcomes, the presence of one or more minor alleles was associated with more severe pain (Table 2). Additional adjustment for patient age and sex did not change the significance of the associations (data not shown).

\section{Association of FKBP5 Polymorphisms with Musculoskeletal Pain after Sexual Assault}

Of the six SNPs associated with both pain outcomes in the MVC discovery cohort, four were associated with overall pain severity six weeks after sexual assault and three were associated with neck pain severity six weeks after sexual assault (Table 3). The same direction of genotype effect in both the MVC and sexual assault cohort was observed in all replicating SNPs. Additional adjustment for patient age did not change the significance and the effect size of the associations (data not shown).

\section{FKBP5 Haplotypes}

Population frequencies for FKBP5 haplotypes were estimated using the six significant SNPs from our larger MVC discovery cohort sample $(\mathrm{n}=949)$ via an expectation-maximization algorithm implemented in HaploView. Results were verified using Bayesian estimation implemented in SAS 9.2. Risk alleles of the SNPs showing the strongest association with persistent pain in both cohorts (including the risk allele at rs 3800373 previously associated with stress-related psychological sequelae $[6,26]$ ) are located on two haplotypes with population frequencies 0.10 and 0.08 (Figure 1).

\section{FKBP5 Genotype and Pain Trajectory after Trauma}

SNP rs2817032, which showed a strong influence on pain outcomes in both cohorts, was used to explore the effect of FKBP5 genotype on pain over time (month prior to trauma, 
early aftermath of trauma, six weeks after trauma). The effect of genotype on overall and neck pain significantly varied by the time of assessment (genotype $\times$ time interaction $\mathrm{p}$ $<0.05)$. The CC/CT genotype was associated with higher neck pain and overall pain 6 weeks after motor vehicle collision and sexual assault $(\mathrm{p}<0.01$, Figure $2, \mathrm{~A}-\mathrm{D})$, but was associated with acute pain in ED in the post-MVC cohort only (Figure 2, B). Interestingly, this genotype was also associated with average overall pain prior to sexual assault (Figure 2, C).

\section{DISCUSSION}

We have shown that genetic variants influencing a key component of the HPA axis, FKBP5, demonstrate a strong and replicable association with musculoskeletal pain outcomes six weeks after MVC and sexual assault. SNPs that are significantly associated with musculoskeletal pain after MVC and sexual assault cohorts are in high linkage disequilibrium and tag two common haplotypes spanning the entire FKBP5 gene [7,22].

SNP rs3800373, which tags haplotypes associated with increased pain after MVC and sexual assault, has been associated with enhanced induction of FKBP5 mRNA by Cortisol [7] and reduced glucocorticoid receptor sensitivity [6]. Because glucocorticoid receptor sensitivity is essential for HPA axis negative feedback inhibition, carriers of the FKBP5 haplotypes associated with increased pain after trauma exposure in our study would be expected to experience more persistent elevation of glucocorticoids in response to stress [30]. Consistent with this hypothesis, these FKBP5 haplotypes have been associated with elevated Cortisol levels after dexamethasone administration [47] or stress exposure [22].

In an animal model of hyperalgesia induced by non-habituating sound stress [24,42], it has been shown that both elevated glucocorticoids and elevated catecholamines after stress exposure are necessary for the development of persistent generalized hyperalgesia [23]. Consistent with our finding of a stronger association between FKBP5 risk haplotypes and pain six weeks after trauma than immediately after trauma, the hyperalgesia developing in this animal model was delayed onset [23]. This hyperalgesia was due to the action of glucorticoids and catecholamines on primary sensory neurons, and appeared to be mediated by stress-induced changes in second messenger signaling pathways [23]. Based on these data, we hypothesize that the increased pain experienced by MVC and sexual assault survivors with FKBP5 risk haplotypes in our study is due, at least in part, to the peripheral effects of elevated glucocorticoids on sensory afferents. In addition, glucocorticoid systems exert an important influence on immune system function [13,44], and FKBP5 risk haplotypes may influence post-stress outcomes in part via mechanism which lead to the increased production of pro-inflammatory mediators (e.g. cytokines). Such mediators may promote hyperalgesia both by sensitizing peripheral and central afferents directly [15,16,29] and by sensitizing CNS neurons via an afferent feedback mechanism [15,16,29,52-54]. FKBP5 risk haplotypes may also affect pain after stress exposure by influencing glucocorticoid pathways in the central nervous system (e.g. references [48,51]).

The molecular mechanisms by which FKBP5 genetic variants affect cell biology remain poorly understood. An FKBP5 allele contained within the risk haplotypes has previously been shown to affect higher FKBP5 protein levels, but not mRNA levels, suggesting that the risk haplotypes may influence mRNA stability rather than transcription [7]. Consistent with this hypothesis, in silico modeling has shown that the FKBP5 risk haplotype variants may alter FKBP5 mRNA folding [36]. Additionally, polymorphism rs3800373 in the 3'untranslated region may interfere with microRNA binding, a common mechanism of posttranscriptional control of gene expression [36]. Finally, rs2817032, showing the strongest association in the replication cohort in our study, appears to be both in the intronic region of 
FKBP5 and in an exon of an overlapping RNA transcript (GeneBank accession number AK093304) [35], which might regulate FKBP5 expression at the post-transcriptional stage.

FkBP5 risk haplotypes were associated with pain prior to trauma in sexual assault survivors, but not in MVC survivors. This discrepancy may be due to the fact that MVC survivors reported relatively little pre-assault pain, reducing power to detect an association between FKBP5 genotype and pre-trauma pain level in this cohort.

Previous studies have identified an association of FKBP5 polymorphisms and PTSD symptom severity after trauma [6,8], and, consistent with previous studies [10,32], PTSD and pain symptoms were positively correlated among trauma survivors in our cohorts (e.g. $\mathrm{r}=0.36, \mathrm{p}<0.001$ for neck pain and $\mathrm{r}=0.42, \mathrm{p}<0.001$ for overall pain in MVC cohort). We repeated MVC cohort analyses excluding those with substantial PTSD symptoms (IES-R score 233)[11] at six weeks, and the effect size of the association between FKBP5 polymorphisms with pain did not diminish (data not shown). Therefore, the association between FKBP5 polymorphisms and pain outcomes was not due to the mild to moderate correlation between pain and PTSD symptoms after trauma.

The results of this study suggest that the FKBP5 molecule (and other molecules which interact with the glucocorticoid receptor) are potential drug targets for the prevention of post traumatic musculoskeletal pain. However, because the effects of these systems and their molecular components are complex, substantial preclinical testing is necessary to establish their safety and potential efficacy prior to any human testing.

Several limitations should be considered when interpreting our study results. First, the size of our replication cohort was small. However, we limited our replication tests to only polymorphisms that were significant across outcomes in the discovery cohort, performed permutation analyses to derive exact p-values, and found consistent evidence of SNP replication that mapped to two risk haplotypes. In addition, we limited our study to European Americans to avoid confounding by population stratification [9], therefore the generalizability of our findings to other race/ethnic groups is unknown. Also, we did not utilize ancestry informative markers in our study, and therefore residual population stratification within our European American cohort is still possible. However, self-report has been shown to be a highly accurate means of determining European American ancestry [46], and all assessed polymorphisms were in Hardy-Weinberg equilibrium, suggesting little, if any, stratification in the studied samples. Adjustment for study site in the regression models was also used to minimize the effect of population variations across geographic regions of the Eastern United States. Finally, our study assessed pain severity six weeks after trauma, but the influence of FKBPS polymorphisms on pain experienced during the months and years after trauma are unknown.

An additional limitation is that we did not assess childhood trauma exposure. In previous studies, self-reported childhood trauma exposure has been shown to interact with FKBP5 polymorphisms to influence the severity of stress-related disorders [6,56]. Our study design differed from these previous studies, in that we evaluated outcomes after a known environmental exposure, rather than assessing previous life trauma as the environmental exposure.

The results of this study suggest that genetic variants in a gene influencing glucocorticoid signal transduction, FKBP5, influence the severity of musculoskeletal pain symptoms experienced during the weeks after two common traumatic events. These findings add important new evidence that HPA axis activation may contribute to the development of persistent musculoskeletal pain symptoms after traumatic events such as MVC and sexual assault, separate from and/or in addition to the effect of any tissue trauma. 


\section{Supplementary Material}

Refer to Web version on PubMed Central for supplementary material.

\section{Acknowledgments}

Funding/Support: Funding for this study was provided by the National Institute of Arthritis, Musculoskeletal, and Skin Diseases (R01 AR056328: Samuel A. McLean) and by the National Center for Research Resources (UL1RR025747: Samuel A. McLean). None of the above funding agencies had any role in the design and conduct of the study, in the collection, management, analysis and interpretation of the data, or in the preparation, review, or approval of the manuscript.

\section{REFERENCE LIST}

1. U.S. Census Bureau, Statistical Abstract of the United States: 2012. 131st Edition. Washington, DC: <http://www.census.gov/compendia/statab/>

2. Ballina LE, Ulirsch JC, Soward AC, Rossi C, Rotolo S, Linnstaedt SD, Heafner T, Foley KA, Batts J, Collette R, Holbrook D, Zelman S, McLean SA. $\mu$-Opioid Receptor Gene A118G Polymorphism Predicts Pain Recovery after Sexual Assault. J Pain. 2013; 14(2):165-171. [PubMed: 23260451]

3. Barrett JC, Fry B, Maller J, Daly MJ. Haploview: analysis and visualization of LD and haplotype maps. Bioinformatics. 2005; 21(2):263-265. [PubMed: 15297300]

4. Benjamini Y, Hochberg Y. Controlling the False Discovery Rate - a Practical and Powerful Approach to Multiple Testing. J Roy Stat Soc B Met. 1995; 57(1):289-300.

5. Bijur PE, Latimer CT, Gallagher EJ. Validation of a verbally administered numerical rating scale of acute pain for use in the emergency department. Acad Emerg Med. 2003; 10(4):390-392. [PubMed: 12670856]

6. Binder EB, Bradley RG, Liu W, Epstein MP, Deveau TC, Mercer KB, Tang Y, Gillespie CF, Heim CM, Nemeroff CB, Schwartz AC, Cubells JF, Ressler KJ. Association of FKBP5 polymorphisms and childhood abuse with risk of posttraumatic stress disorder symptoms in adults. JAMA. 2008; 299(11):1291-1305. [PubMed: 18349090]

7. Binder EB, Salyakina D, Lichtner P, Wochnik GM, Ising M, Putz B, Papiol S, Seaman S, Lucae S, Kohli MA, Nickel T, Kunzel HE, Fuchs B, Majer M, Pfennig A, Kern N, Brunner J, Modell S, Baghai T, Deiml T, Zill P, Bondy B, Rupprecht R, Messer T, Kohnlein O, Dabitz H, Bruckl T, Muller N, Pfister H, Lieb R, Mueller JC, Lohmussaar E, Strom TM, Bettecken T, Meitinger T, Uhr M, Rein T, Holsboer F, Muller-Myhsok B. Polymorphisms in FKBP5 are associated with increased recurrence of depressive episodes and rapid response to antidepressant treatment. Nat Genet. 2004; 36(12):1319-1325. [PubMed: 15565110]

8. Boscarino JA, Erlich PM, Hoffman SN, Rukstalis M, Stewart WF. Association of FKBP5, COMT and CHRNA5 polymorphisms with PTSD among outpatients at risk for PTSD. Psychiatry Res. 2011; 188(1):173-174. [PubMed: 21440309]

9. Cardon LR, Palmer LJ. Population stratification and spurious allelic association. Lancet. 2003; 361(9357):598-604. [PubMed: 12598158]

10. Clapp JD, Beck JG, Palyo SA, Grant DM. An examination of the synergy of pain and PTSD on quality of life: additive or multiplicative effects? Pain. 2008; 138(2):301-309. [PubMed: 18280044]

11. Creamer M, Bell R, Failla S. Psychometric properties of the Impact of Event Scale -Revised. Behav Res Ther. 2003; 41(12):1489-1496. [PubMed: 14705607]

12. de Bakker PI, Yelensky R, Pe'er I, Gabriel SB, Daly MJ, Altshuler D. Efficiency and power in genetic association studies. Nat Genet. 2005; 37(11):1217-1223. [PubMed: 16244653]

13. Elenkov IJ, Wilder RL, Chrousos GP, Vizi ES. The sympathetic nerve-an integrative interface between two supersystems: the brain and the immune system. Pharmacol Rev. 2000; 52(4):595638. [PubMed: 11121511]

14. Ferrari LF, Levine E, Levine JD. Independent Contributions of Alcohol and Stress Axis Hormones to Painful Peripheral Neuropathy. Neurosci. 2013; 228:409-417. 
15. Ferreira SH. The role of interleukins and nitric oxide in the mediation of inflammatory pain and its control by peripheral analgesics. Drugs. 1993; 46(Suppl 1):1-9. [PubMed: 7506142]

16. Fukuoka H, Kawatani M, Hisamitsu T, Takeshige C. Cutaneous hyperalgesia induced by peripheral injection of interleukin-1 beta in the rat. Brain Res. 1994; 657(1-2):133-140. [PubMed: 7820610]

17. Gaab J, Baumann S, Budnoik A, Gmunder H, Hottinger N, Ehlert U. Reduced reactivity and enhanced negative feedback sensitivity of the hypothalamus-pituitary-adrenal axis in chronic whiplash-associated disorder. pain. 2005; 119(1-3):219-224. [PubMed: 16298068]

18. Geiss A, Rohleder N, Kirschbaum C, Steinbach K, Bauer HW, Anton F. Predicting the failure of disc surgery by a hypofunctional HPA axis: evidence from a prospective study on patients undergoing disc surgery. Pain. 2005; 114(1-2):104-117. [PubMed: 15733636]

19. Golding JM. Sexual assault history and physical health in randomly selected Los Angeles women. Health Psychol. 1994; 13(2):130-138. [PubMed: 8020456]

20. Hartling L, Brison RJ, Ardern C, Pickett W. Prognostic value of the Quebec Classification of Whiplash-Associated Disorders. Spine (Phila Pa 1976). 2001; 26(1):36-41. [PubMed: 11148643]

21. Holm LW, Carroll LJ, Cassidy JD, Hogg-Johnson S, Cote P, Guzman J, Peloso P, Nordin M, Hurwitz E, van der Velde G, Carragee E, Haldeman S. The burden and determinants of neck pain in whiplash-associated disorders after traffic collisions: results of the Bone and Joint Decade 2000-2010 Task Force on Neck Pain and Its Associated Disorders. Spine (Phila Pa 1976). 2008; 33(4 Suppl):S52-S59. [PubMed: 18204401]

22. Ising M, Depping AM, Siebertz A, Lucae S, Unschuld PG, Kloiber S, Horstmann S, Uhr M, Muller-Myhsok B, Holsboer F. Polymorphisms in the FKBP5 gene region modulate recovery from psychosocial stress in healthy controls. Eur J Neurosci. 2008; 28(2):389-398. [PubMed: 18702710]

23. Khasar SG, Burkham J, Dina OA, Brown AS, Bogen O, Alessandri-Haber N, Green PG, Reichling DB, Levine JD. Stress induces a switch of intracellular signaling in sensory neurons in a model of generalized pain. J Neurosci. 2008; 28(22):5721-5730. [PubMed: 18509033]

24. Khasar SG, Green PG, Levine JD. Repeated sound stress enhances inflammatory pain in the rat. Pain. 2005; 116(1-2):79-86. [PubMed: 15936144]

25. Kilpatrick, D.; Edmunds, C.; Seymour, A. Rape in America: A Report to the Nation. Arlington, Virginia: National Victim Center; 1992.

26. Koenen KC, Saxe G, Purcell S, Smoller JW, Bartholomew D, Miller A, Hall E, Kaplow J, Bosquet M, Moulton S, Baldwin C. Polymorphisms in FKBP5 are associated with peritraumatic dissociation in medically injured children. Mol Psychiatry. 2005; 10(12):1058-1059. [PubMed: 16088328]

27. Lin S, Cutler DJ, Zwick ME, Chakravarti A. Haplotype inference in random population samples. Am J Hum Genet. 2002; 71(5):1129-1137. [PubMed: 12386835]

28. Linton SJ. A population-based study of the relationship between sexual abuse and back pain: establishing a link. Pain. 1997; 73(1):47-53. [PubMed: 9414056]

29. Maier SF, Wiertelak EP, Martin D, Watkins LR. Interleukin-1 mediates the behavioral hyperalgesia produced by lithium chloride and endotoxin. Brain Res. 1993; 623(2):321-324. [PubMed: 8221116]

30. McBeth J, Chiu YH, Silman AJ, Ray D, Morriss R, Dickens C, Gupta A, Macfarlane GJ. Hypothalamic-pituitary-adrenal stress axis function and the relationship with chronic widespread pain and its antecedents. Arthritis Res Ther. 2005; 7(5):R992-R1000. [PubMed: 16207340]

31. McBeth J, Silman AJ, Gupta A, Chiu YH, Ray D, Morriss R, Dickens C, King Y, Macfarlane GJ. Moderation of psychosocial risk factors through dysfunction of the hypothalamic-pituitary-adrenal stress axis in the onset of chronic widespread musculoskeletal pain: findings of a population-based prospective cohort study. Arthritis Rheum. 2007; 56(1):360-371. [PubMed: 17195240]

32. McFarlane AC, Atchison M, Rafalowicz E, Papay P. Physical symptoms in post-traumatic stress disorder. J Psychosom Res. 1994; 38(7):715-726. [PubMed: 7877126]

33. McLean SA, Soward AC, Ballina LE, Rossi C, Rotolo S, Wheeler R, Foley KA, Batts J, Casto T, Collette R, Holbrook D, Goodman E, Rauch SA, Liberzon I. Acute severe pain is a common consequence of sexual assault. J Pain. 2012; 13(8):736-741. [PubMed: 22698980] 
34. Myers B, Greenwood-Van Meerveld B. Divergent effects of amygdala glucocorticoid and mineralocorticoid receptors in the regulation of visceral and somatic pain. Am J Physiol Gastrointest Liver Physiol. 2010; 298(2):G295-G303. [PubMed: 19875699]

35. Ota T, Suzuki Y, Nishikawa T, Otsuki T, Sugiyama T, Irie R, Wakamatsu A, Hayashi K, Sato H, Nagai K, Kimura K, Makita H, Sekine M, Obayashi M, Nishi T, Shibahara T, Tanaka T, Ishii S, Yamamoto J, Saito K, Kawai Y, Isono Y, Nakamura Y, Nagahari K, Murakami K, Yasuda T, Iwayanagi T, Wagatsuma M, Shiratori A, Sudo H, Hosoiri T, Kaku Y, Kodaira H, Kondo H, Sugawara M, Takahashi M, Kanda K, Yokoi T, Furuya T, Kikkawa E, Omura Y, Abe K, Kamihara K, Katsuta N, Sato K, Tanikawa M, Yamazaki M, Ninomiya K, Ishibashi T, Yamashita H, Murakawa K, Fujimori K, Tanai H, Kimata M, Watanabe M, Hiraoka S, Chiba Y, Ishida S, Ono Y, Takiguchi S, Watanabe S, Yosida M, Hotuta T, Kusano J, Kanehori K, Takahashi-Fujii A, Hara H, Tanase TO, Nomura Y, Togiya S, Komai F, Hara R, Takeuchi K, Arita M, Imose N, Musashino K, Yuuki H, Oshima A, Sasaki N, Aotsuka S, Yoshikawa Y, Matsunawa H, Ichihara T, Shiohata N, Sano S, Moriya S, Momiyama H, Satoh N, Takami S, Terashima Y, Suzuki O, Nakagawa S, Senoh A, Mizoguchi H, Goto Y, Shimizu F, Wakebe H, Hishigaki H, Watanabe T, Sugiyama A, Takemoto M, Kawakami B, Watanabe K, Kumagai A, Itakura S, Fukuzumi Y, Fujimori Y, Komiyama M, Tashiro H, Tanigami A, Fujiwara T, Ono T, Yamada K, Fujii Y, Ozaki K, Hirao M, Ohmori Y, Kawabata A, Hikiji T, Kobatake N, Inagaki H, Ikema Y, Okamoto S, Okitani R, Kawakami T, Noguchi S, Itoh T, Shigeta K, Senba T, Matsumura K, Nakajima Y, Mizuno T, Morinaga M, Sasaki M, Togashi T, Oyama M, Hata H, Komatsu T, Mizushima-Sugano J, Satoh T, Shirai Y, Takahashi Y, Nakagawa K, Okumura K, Nagase T, Nomura N, Kikuchi H, Masuho Y, Yamashita R, Nakai K, Yada T, Ohara O, Isogai T, Sugano S. Complete sequencing and characterization of 21,243 full-length human cDNAs. Nat Genet. 2004; 36(1):40-45. [PubMed: 14702039]

36. Pelleymounter LL, Moon I, Johnson JA, Laederach A, Halvorsen M, Eckloff B, Abo R, Rossetti S. A novel application of pattern recognition for accurate SNP and indel discovery from highthroughput data: targeted resequencing of the glucocorticoid receptor co-chaperone FKBP5 in a Caucasian population. Mol Genet Metab. 2011; 104(4):457-469. [PubMed: 21917492]

37. Platts-Mills TF, Ballina L, Bortsov AV, Soward A, Swor RA, Jones JS, Lee DC, Peak DA, Domeier RM, Rathlev NK, Hendry PL, McLean SA. Using emergency department-based inception cohorts to determine genetic characteristics associated with long term patient outcomes after motor vehicle collision: methodology of the CRASH study. BMC Emerg Med. 2011; 11:14. [PubMed: 21943293]

38. Platts-Mills TF, Hunold KM, Esserman DA, Sloane PD, McLean SA. Motor vehicle collisionrelated emergency department visits by older adults in the United States. Acad Emerg Med. 2012; 19(7):821-827. [PubMed: 22724382]

39. Pratt WB, Toft DO. Steroid receptor interactions with heat shock protein and immunophilin chaperones. Endocr Rev. 1997; 18(3):306-360. [PubMed: 9183567]

40. Resnick HS, Kilpatrick DG, Dansky BS, Saunders BE, Best CL. Prevalence of civilian trauma and posttraumatic stress disorder in a representative national sample of women. J Consult Clin Psychol. 1993; 61(6):984-991. [PubMed: 8113499]

41. Ronnen HR, de Korte PJ, Brink PR, van der Bijl HJ, Tonino AJ, Franke CL. Acute whiplash injury: is there a role for MR imaging?-a prospective study of 100 patients. Radiology. 1996; 201(1):93-96. [PubMed: 8816527]

42. Singh VB, Corley KC, Phan TH, Boadle-Biber MC. Increases in the activity of tryptophan hydroxylase from rat cortex and midbrain in response to acute or repeated sound stress are blocked by adrenalectomy and restored by dexamethasone treatment. Brain Res. 1990; 516(1):66-76. [PubMed: 2364282]

43. Stein MB, Lang AJ, Laffaye C, Satz LE, Lenox RJ, Dresselhaus TR. Relationship of sexual assault history to somatic symptoms and health anxiety in women. Gen Hosp Psychiatry. 2004; 26(3): 178-183. [PubMed: 15121345]

44. Sternberg EM. Neural regulation of innate immunity: a coordinated nonspecific host response to pathogens. Nat Rev Immunol. 2006; 6(4):318-328. [PubMed: 16557263]

45. Suissa S, Harder S, Veilleux M. The relation between initial symptoms and signs and the prognosis of whiplash. Eur Spine J. 2001; 10(1):44-49. [PubMed: 11276835] 
46. Tang H, Quertermous T, Rodriguez B, Kardia SL, Zhu X, Brown A, Pankow JS, Province MA, Hunt SC, Boerwinkle E, Schork NJ, Risch NJ. Genetic structure, self-identified race/ethnicity, and confounding in case-control association studies. Am J Hum Genet. 2005; 76(2):268-275. [PubMed: 15625622]

47. Touma C, Gassen NC, Herrmann L, Cheung-Flynn J, Bull DR, Ionescu IA, Heinzmann JM, Knapman A, Siebertz A, Depping AM, Hartmann J, Hausch F, Schmidt MV, Holsboer F, Ising M, Cox MB, Schmidt U, Rein T. FK506 binding protein 5 shapes stress responsiveness: modulation of neuroendocrine reactivity and coping behavior. Biol Psychiatry. 2011; 70(10):928-936. [PubMed: 21907973]

48. Tran L, Wiskur B, Greenwood-Van Meerveld B. The role of the anteriolateral bed nucleus of the stria terminalis in stress-induced nociception. Am J Physiol Gastrointest Liver Physiol. 2012; 302(11):G1301-G1309. [PubMed: 22492693]

49. van Zuiden M, Geuze E, Willemen HL, Vermetten E, Maas M, Amarouchi K, Kavelaars A, Heijnen CJ. Glucocorticoid Receptor Pathway Components Predict Posttraumatic Stress Disorder Symptom Development: A Prospective Study. Biol Psychiatry. 2012; 71(4):309-316. [PubMed: 22137507]

50. Waigandt A, Wallace D, Phelps L, Miller DA. Impact of sexual assault on physical health status. J Traum Stress. 1990; 3:93-102.

51. Wang S, Lim G, Zeng Q, Sung B, Ai Y, Guo G, Yang L, Mao J. Expression of central glucocorticoid receptors after peripheral nerve injury contributes to neuropathic pain behaviors in rats. J Neurosci. 2004; 24(39):8595-8605. [PubMed: 15456833]

52. Watkins LR, Goehler LE, Relton J, Brewer MT, Maier SF. Mechanisms of tumor necrosis factoralpha (TNF-alpha) hyperalgesia. Brain Res. 1995; 692(1-2):244-250. [PubMed: 8548310]

53. Watkins LR, Maier SF, Goehler LE. Immune activation: the role of pro-inflammatory cytokines in inflammation, illness responses and pathological pain states. Pain. 1995; 63(3):289-302. [PubMed: 8719529]

54. Watkins LR, Wiertelak EP, Goehler LE, Smith KP, Martin D, Maier SF. Characterization of cytokine-induced hyperalgesia. Brain Res. 1994; 654(1):15-26. [PubMed: 7982088]

55. Wochnik GM, Rüegg J, Abel GA, Schmidt U, Holsboer F, Rein T. FK506-binding proteins 51 and 52 differentially regulate dynein interaction and nuclear translocation of the glucocorticoid receptor in mammalian cells. J Biol Chem. 2005; 280(6):4609-4616. [PubMed: 15591061]

56. Xie P, Kranzler HR, Poling J, Stein MB, Anton RF, Farrer LA, Gelernter J. Interaction of FKBP5 with childhood adversity on risk for post-traumatic stress disorder. Neuropsychopharmacology. 2010; 35(8):1684-1692. [PubMed: 20393453] 


\section{SUMMARY}

This study demonstrates an association between genetic polymorphisms in the gene coding for a key regulatory molecule in the hypothalamic-pituitary-adrenal (HPA) axis and persistent pain in two cohorts experiencing two different types of trauma (motor vehicle collision and sexual assault). 


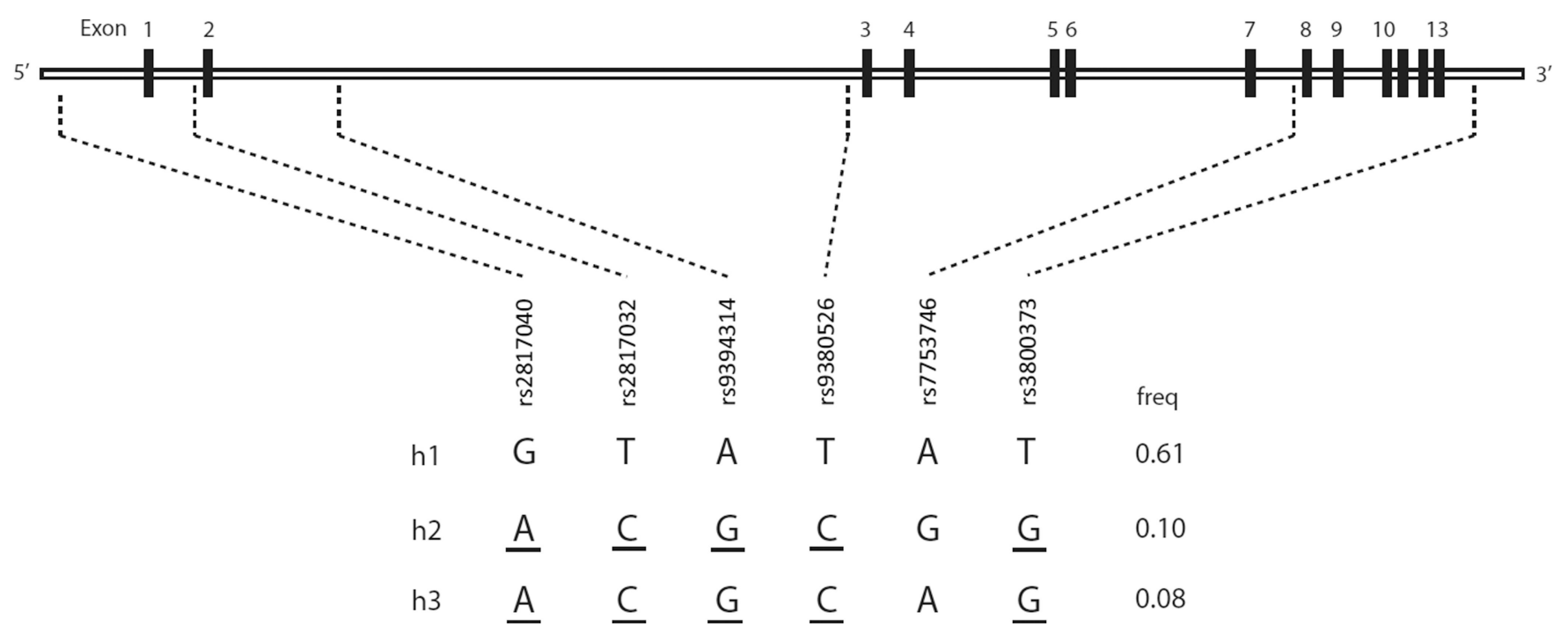

Figure 1. FKBP5 haplotypes

FKBP5 haplotypes were estimated from the six SNP genotypes (rs3800373, rs7753746, rs9380526, rs9394314, rs2817032, and rs2817040) predicting overall pain and neck pain six weeks after trauma exposure in the motor vehicle collision cohort. Haplotype frequencies are estimated using the expectation-maximization algorithm. Only haplotypes with a frequency $>0.05$ are shown (79\% of all haplotypes). Risk alleles of the replicated SNPs are underlined. Rs9380526 was most significantly associated with overall pain intensity and neck pain at week 6 after motor vehicle collision in the motor vehicle collision cohort. Rs 2817032 showed the strongest association with overall pain at week 6 after sexual assault. Rs3800373 has been previously reported in the literature to predict PTSD [6]. The results show that all risk alleles belong to two haplotypes ( $\mathrm{h} 2$ and $\mathrm{h} 3$ ) with combined frequency 0.18 . 


\section{Motor Vehicle Collision Cohort}
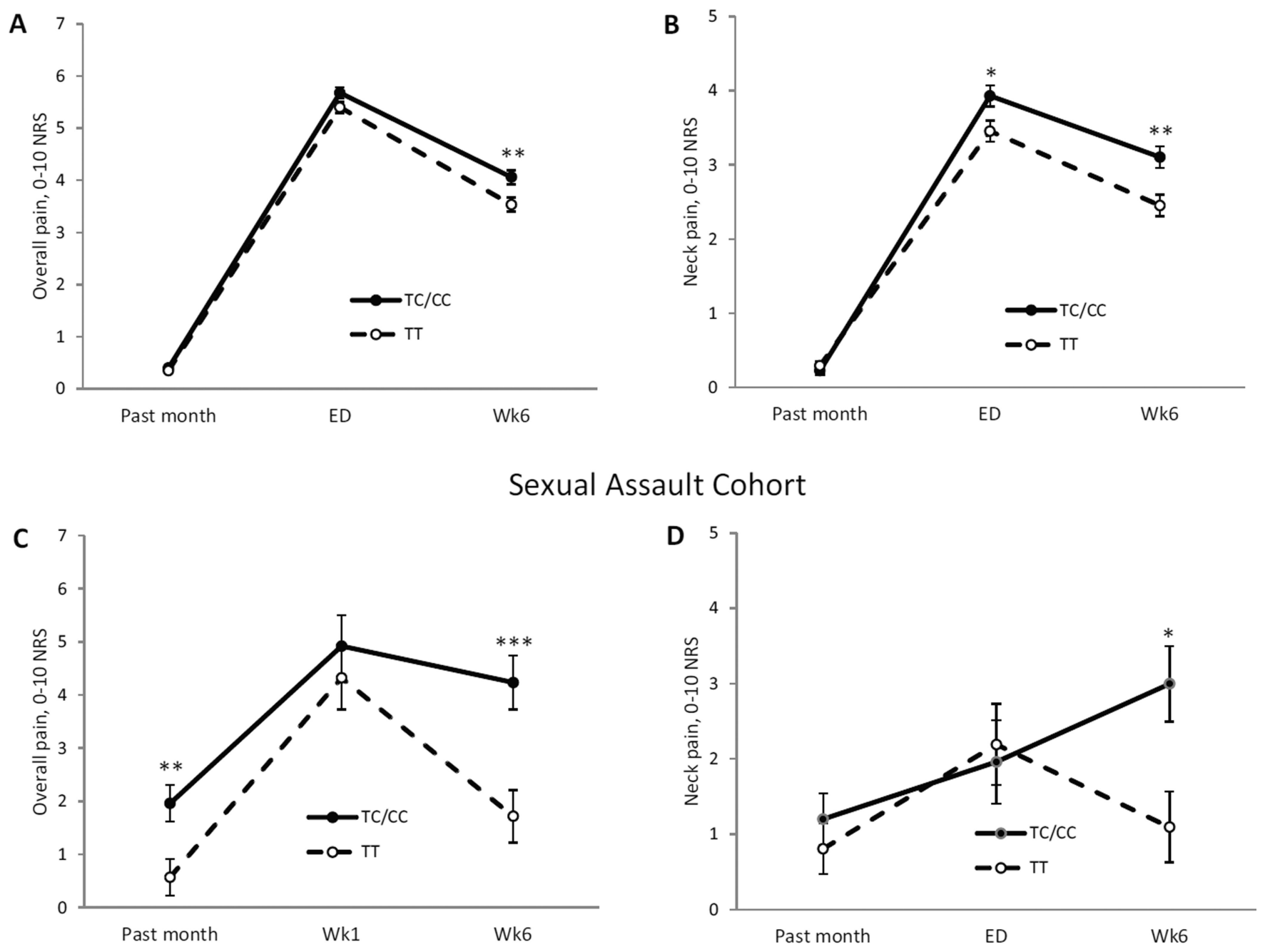

Figure 2. Overall musculoskeletal pain trajectories and neck pain trajectories

Overall musculoskeletal pain trajectories and neck pain trajectories by rs2817032 genotype in the motor vehicle collision cohort (A, B) and sexual assault cohort (C, D). A), B) After motor vehicle collision, the presence of one or more copies of the $\mathrm{C}$ allele was associated acute neck pain in emergency department (ED) $(\mathrm{p}<0.05)$ and with overall and neck pain at six weeks $(p<0.01)$. Effect of the genotype on pain intensity varied by the time of assessment (assessment time $\times$ genotype interaction term $\mathrm{p}<0.05$ ). In the sexual assault cohort, the presence of one or more copies of the $\mathrm{C}$ allele was associated with overall pain during the month prior to assault $(\mathrm{p}<0.01)$ and with overall pain $(\mathrm{p}<0.001)$ and neck pain $(\mathrm{p}<0.01)$ at six weeks. $* \mathrm{p}<0.05 ; * * \mathrm{p}<0.01 ; * * * \mathrm{p}<0.001$ 
Table 1

Baseline characteristics of study participants

\begin{tabular}{lcc}
\hline Characteristic & $\begin{array}{c}\text { Motor Vehicle } \\
\text { Collision Cohort }\end{array}$ & $\begin{array}{c}\text { Sexual Assault } \\
\text { Cohort }\end{array}$ \\
\hline Enrolled, n & 949 & 53 \\
Age, years, mean(SD) & $36(13)$ & $27(8)$ \\
Females, n(\%) & $575(61)$ & $53(100)$ \\
Education, n(\%) & & \\
8-11 yrs & $42(4)$ & $6(11)$ \\
HS & $184(19)$ & $6(11)$ \\
Post-HS & $57(6)$ & $0(0)$ \\
Some college & $311(33)$ & $30(57)$ \\
College & $237(25)$ & $8(15)$ \\
Post-college & $113(12)$ & $3(7)$ \\
Overall pain, 0-10 NRS, mean(SD) & \\
Past month & $0.4(0.5)$ & $1.4(1.9)$ \\
ED (week 1 for SA cohort) & $5.5(2.4)$ & $4.8(3.0)$ \\
Week 6 & $3.8(2.8)$ & $3.2(2.9)$ \\
Neck pain, 0-10 NRS, mean(SD) & & \\
Past month & $0.3(1.2)$ & $1.0(1.7)$ \\
ED & $3.7(3.1)$ & $2.0(2.7)$ \\
Week 6 & $2.8(3.0)$ & $1.9(2.4)$ \\
\hline
\end{tabular}

HS, high school; NRS. numeric rating scale; ED, emergency department 
